Luísa Pelucio

O- hitps://orcid.org/0000-0002-7928-2578

Marcia Cristina Nascimento

Dourado2

๑nttps://orcid.org/0000-0001-6267-8202

Antonio Egidio Nardi ${ }^{1,2}$

Ohttps://orcid.org/0000-0002-2152-4669

Michelle Levitan'

(O) https://orcid.org/0000-0002-1819-9885

\section{Psychological home care for type II Schizencephaly: technical and theoretical aspects}

\author{
Atenção psicológica domiciliar com esquizencefalia \\ tipo Il: aspectos técnicos e teóricos
}

DOl: 10.1590/0047-2085000000352

\section{RESUMO}

A esquizencefalia é um defeito ou malformação congênita do desenvolvimento extremamente raro, caracterizado por fendas anormais nos hemisférios cerebrais, estendendo-se do córtex aos ventrículos, que podem ser unilaterais ou bilaterais. Este relato de caso descreve as características gerais de um programa de atenção psicológica domiciliar, relatando os principais elementos teóricos e técnicos de um paciente de 12 anos de idade com esquizencefalia tipo II. Os objetivos do tratamento psicológico domiciliar eram a aceitação da nova realidade do tratamento, a redução da agressividade e da ansiedade e o apoio psicológico ao paciente e à família. No atendimento psicológico domiciliar, a consciência do paciente sobre a doença foi desenvolvida, juntamente com a orientação familiar, psicoeducação, técnicas de relaxamento e distração cognitiva. Pode-se observar que houve melhora significativa do estado afetivo e emocional no quadro clínico do paciente.

\section{PALAVRAS-CHAVE}

Atenção domiciliar, tratamento psicológico, comunicação.

\section{ABSTRACT}

Schizencephaly is an extremely rare developmental birth defect or malformation characterized by abnormal clefts in the cerebral hemispheres of the brain, extending from the cortex to the ventricles, which may be unilateral or bilateral. This case report describes the general characteristics of a psychological home care program, reporting the main theoretical and technical elements in a 12-years-old case of type II Schizencephaly. The aims of the psychological home treatment were acceptance of the new treatment reality, a reduction in aggression and anxiety, and psychological support for the patient and family. In the psychological home care, patient's awareness of illness was developed, along with family orientation, psychoeducation, relaxation techniques, and cognitive distraction. It can be observed that a significant improvement in the affective and emotional state was achieved within the patient's clinical framework.

\section{KEYWORDS}

Home care, psychological treatment, communication. 


\section{INTRODUCTION}

Schizencephaly is a congenital defect or malformation that can cause motor deficits, seizures, cognitive deficits, lack of movement, feeding disturbances, congenital hemianopsias, developmental dyslexia, and psychiatric disturbances'. It was first described in 1946 by Yakovlev and Wadsworth in their work on cadavers, who coined the name "schizencephaly" as congenital clefts in the cerebral mantle2. Schizencephaly is also associated in some cases with microcephaly, hydrocephalus, or other malformations such as septo-optic dysplasia ${ }^{3,4}$. The occurrence of various insults from the third to the fifth month of gestation such as ischemia, maternal trauma, germline mutations (EMX2 gene3 ), intrauterine infections, and exposure to drugs (especially alcohol) ${ }^{4}$ cause defects in neuroblast migration, which can result in Schizencephaly. This condition is present at birth and manifests early in life ${ }^{5}$.

Home care is a modality in which care is provided to the patient-family dyad at home. It is carried out by a multiprofessional and interdisciplinary team that seeks to understand and manage the patient's situations based on physical, psychological, social, and spiritual aspects'. Usually, children with life-shortening serious illnesses and medically complex care needs are increasingly cared for by their families at home $e^{6,7}$.

Psychological care has been increasingly offered among services provided at home care. Psychological home care aims to manage emotional and adaptation difficulties related to health problems in the family environment and to help in the systematic participation of various professionals in the care offered at home ${ }^{8-10}$. Psychological home care also seeks to contribute to the optimization of hospital beds and out-patient care, aimed at reducing costs; to reintegrate the patient in their nuclear family and a network of support; to provide humanized holistic care, through a greater approximation of the healthcare team and the family, and to stimulate greater participation of the patient and their family in the proposed treatment ${ }^{11,12}$.

Psychological home care begins with a brief descriptive presentation of the case by the professional responsible for the team, followed by an admission visit when the psychological demand is passed on to the psychologist. For the first visit, one or more family members or caregivers are requested to understand the patient's health conditions and emotional and cognitive resources ${ }^{13}$. The first meeting represents a broad view of the case, with the understanding of the initially relevant information, such as the neighborhood, the residence, the layout of the rooms, the number of people, the objects, the colors, and the organization of the house. The way the family receives the psychologist and the room the patient and the caregiver, or person responsible, choose for the meeting already demonstrates characteristics to be analyzed. Some of these characteristics are the interactions and conflicts between members of the household, their conduct with the professionals, concerns, and acceptance and management of reality ${ }^{14,15}$.

Psychological care at home can contribute to the comprehensive rehabilitation of people with disabilities. Many studies use innovative technologies for an integrative and more global contribution to improvement from each patient's perspective ${ }^{16}$. Many forms of home technology aiming at rehabilitation have been conceived, and several human factors are essential for its application and the resources for its use. The studies reviewed on the technology included games, telerehabilitation, robotic devices, virtual reality devices, sensors, and tablets ${ }^{16}$.

The setting of the psychological home treatment is a set of procedures to organize and normalize the therapeutic process established during the first contact, such as rules regarding time, place, and frequency of sessions, and the appropriate roles for each member of the relatioship ${ }^{17,18}$. In the therapeutic environment at home, interference may occur during treatment. This aspect requires that the psychologist should have a flexible attitude and know how to deal with the unexpectedness of time or people in their care within the patient's clinical conditions. The psychologist should also guarantee that the patient is comfortable and has the privacy to share their thoughts and emotions. Care should also be taken regarding closing the door to the room, the lighting, and any sounds that may be present ${ }^{19-23}$.

In this context, this case report describes the general characteristics of a psychological home care program, reporting the main theoretical and technical elements in a case of type II unilateral right open-lip Schizencephaly.

\section{Clinical description}

The patient is a 12-year-old female, with a diagnosis of type II schizencephaly, since pregnancy. The disease was diagnosed prenatally and confirmed at birth when the necessary clinical care began. After birth (normal labor, 1.540 $\mathrm{kg}$, and $41 \mathrm{~cm}$ ), the patient remained hospitalized for 30 days. The initial perception of the family was of a baby with little interaction. The child received all the necessary care but did not develop accordingly. In early childhood, she presented some preserved cognitive functions such as orientation, awareness, attention, concentration, memory, and language. However, her development was characterized as slower than children of the same age, with progressive neurological deficits in attention, concentration, and coordination, in an irreversible clinical condition.

The patient's childhood was marked by constant family care with treatment for improving the development. She underwent eight orthopedic surgeries, besides numerous consultations for motor and respiratory development. 
Physiotherapeutic and speech treatment were also sought to stimulate general development. The patient also experienced psychomotor difficulties, using a wheelchair since she was two years old and undergoing psychomotor stimulation and treatment since early childhood. Currently, the patient's right arm is more developed and she experiences difficulties in moving the other limbs. Due to respiratory limitations, a tracheostomy was also necessary, which upset and embarrassed the patient, who then did not want to receive visitors.

The patient's parents divorced during her early childhood; both remarried and demonstrate a good understanding of her needs. The patient had a good relationship with her mother and stepfather, with whom she lives, and with her father. When he visits, she asks to be embraced and wants him to do everything, such as administer her medication, change her diaper or feed her.

When she needs something in her room, she points to it; she shows things and gesticulates all the time to be understood. A very interesting aspect is that she never stops showing, gesticulating, or making signals until she is understood.

The patient even managed to start school and did primary education. She liked the school environment, and the social contact with friends was extremely positive for her condition and history. She received the help of a mediator for her educational accompaniment, went to activities and classes in her wheelchair.

At age 10, her activities stopped due to a worsening in her motor development. She underwent two more surgeries and spent three months in the hospital. It was surgery on the bone part to place the pins and better support her spine and limbs. After discharge, the medical recommendation was to remain under home care with a multidisciplinary team. At that time, guidance was given regarding care and the patient's needs at home. The patient used aspirators, nebulizers, oxygen concentrators, mechanical ventilator, hospital bed, aspiration material, tracheostomy tube, and gastrostomy tube. Her symptoms varied from motor and respiratory difficulties to deglutition and gastric compromise. Besides, she was very tearful and bothered by the reduction in hospital visits. She also showed increased aggressive behavior and anxiety, which were not present before the prolonged hospitalization.

\section{Psychological treatment}

Home care began in February 2015, after hospital discharge. Home care began with a multidisciplinary team composed of a doctor, a psychologist, a nurse, nursing technicians, a nutritionist, a physiotherapist, a speech therapist, and a social worker. Team meetings were often necessary to exchange information and understand the needs and difficulties of the patient. The psychologist also had the function of an interlocutor of the patient's view, especially given her difficulties in communicating with the multidisciplinary team.

Firstly, an interview was conducted to understand her mother's demands as she was the family caregiver. She was concerned about completely understanding the case and collaborating with the team and, above all, with her daughter. Finally, the informed consent form was signed and explained to her mother and guardian.

The patient's relationship with the nursing technicians who worked 12 and 24 hour shifts was positive. She liked to paint, draw, and play being at school; she also loved watching cartoons, films, videos, and music. Music, especially, made her dance in bed, moving as well as she could. She demonstrated well-being in the company of the affective and attentive professionals. Conversely, she was agitated with more serious and reserved professionals.

In the first psychological session, the patient was still adapting to the changes and did not understand how the treatment would be. During this first contact, the process of home therapy was explained to the mother, with a simple presentation of the treatment possibilities and interventional management. The patient's demands and developmental history were also understood, and there was a brief preliminary contact with the patient as an introduction and welcome. The treatment aims the acceptance of the new treatment reality, a reduction in aggression and anxiety, and psychological support for the patient and family.

The psychological treatment occurred weekly, with a duration of 45 to 50 minutes. During the following sessions, the patient was flexible, demonstrating through her communication and gestures if there had been changes in the team, the family, or the clinical condition. In addition, she presented preserved awareness and orientation. During these sessions, it was possible to develop an empathetic therapeutic relationship through weekly contact and establish a patient/therapist bond, improving understanding of the patient's communication.

Psychological treatment was conducted for 5 years (between 2015 and 2020). During this time, the patient developed a solid, positive therapeutic relationship, as did the mother, whose need to speak at the end of each consultation for emotional support and understanding of the relationship and management of her daughter, was welcomed.

During the sessions, psychoeducation was used, an intervention that enables education and orientation to understand change and new functional articulation, with improvement being obtained.

Regarding anxiety management, diaphragmatic breathing was used, a relaxation and mindfulness technique to maintain a state of emotional tranquility. This management 
was done in a short form to remind the patient to stay calm, with mental images for greater relaxation intensity along with psychoeducational cards stuck on the walls of the bedroom with images of calm people and breathing to assist in cognitive understanding to change behavior.

The patient demonstrated anxiety through behavior such as fidgeting, picking at wounds or around nails, or the corner of the mouth, going so far as injuring herself and being diagnosed with Skin-Picking (Excoriation disorder ${ }^{20}$. She also presented difficulties in waiting, often calling or articulating many times until being attended. These behaviors were also worked on through diaphragmatic breathing and psychoeducation, which greatly assisted in managing and improving the acquisition of the new behavior.

The patient's aggressive behavior appeared when there was a need to manipulate her body, as in the stretching done during physiotherapy or speech treatment activities. When she did not like it, she would try to grab or bite the person's moving her body to stop the exercise or some other form of care. On conversing with the patient regarding this aggression, she demonstrated an understanding, indicating that she did it because she did not want them to move her body where it caused pain. As part of treatment, it was explained to her in different, ludic and educative ways that she needed new, more adaptive behavior to demonstrate what she felt. Behavioral training was initiated with cards about its necessity and the importance of the professionals providing the care that required handling her body.

The process of choice of psychological techniques was made through observation of the clinical necessities of the patient. As a result, the aim of minimizing anxiety was achieved through relaxation, and cognitive distraction techniques and improvements in aggression and emotional maturity were made through the choice of psychoeducation techniques.

The difficulties of psychological home care were mainly concerning the patient's clinical condition, as pauses were often to clean and insert the feeding tube, the arrival of a visitor, or medication administration. However, difficulty in the treatment process only occurred upon ending the sessions since the patient did not like when the professionals left. This point was explained and elaborated at the end of all sessions.

It is important to highlight that the patient did not have a diagnosed learning disability, but because of her health issues, hospitalizations, and motor and physical impairments, the school was paralyzed, which hampered the entire teaching and learning process.

In 2017, after two years of psychological home care, with the help of the family and the reinforcement of orientations on being affective and not being aggressive with the professionals, a significant improvement was achieved with the remission of aggressive behaviors, using psychoeducation on empathy, calmness management, and breathing.

The following year, 2018, the patient moved from the house. Preparation was discussed with the family. The patient's adaptation was positive, with all the organization of the new environment and handling of equipment and instruments necessary for her care. Her mother had some concerns about the change as they lived close to family and the patient was familiar with her environment. Nevertheless, with all the orientation and prior management, the move occurred without problems.

In 2018, after three years of psychological treatment, the patient's clinical medical condition worsened, with convulsions and a worsening of respiratory function, requiring hospitalization, which became prolonged. The patient returned home after two months in hospital, during which time her home care was interrupted. She returned with a respirator plugged into her tracheostomy and respiratory fatigue. All team members were informed of the greater complexity of the patient's clinical condition. She spent a large part of the day sleeping with symptoms of listlessness, drowsiness, and physical weakness.

After some weeks at home, the patient demonstrated as having recovered more, although she remained listless, weak, and disinterested in everything she had previously enjoyed, such as drawing, painting, and watching cartoons. On returning to psychological treatment, a behavioral assessment was conducted and stimuli were offered to evaluate the presence of symptoms of depression, which were dismissed. The patient showed herself to be interested in picking up a pencil, a notebook, her teddy bears, and games, but she ended up falling asleep with the things in her hand.

Her medication and her respiratory apparatus were adjusted in a team meeting and she returned to be more energetic and lively. Then, she returned to moving around to music, laughing at cartoons, and asking for things as she had before. Besides, team training and orientation were conducted to update everyone concerning the new care demands and the changes since hospitalization.

There were also shorter admissions to the hospital for examinations and changing tubes, but these did not affect the patient's condition. The psychological interventions were implemented, with a return to psychoeducation, relaxation techniques, and cognitive distraction. At the beginning of 2019, the patient stabilized emotionally, presenting more adaptive and better managed behavior within herself, her family, and the home care team.

During 2019, the patient was more resilient; not complaining of pain or discomfort. She only complained when people with whom she had a good relationship took 
a long time to arrive at her home. She was affective, being emotionally connected to her social and family relationships. She was also cheerful and more receptive to visitors. In the treatment of the patient, the professionals involved reported learning to deal with technical conditions and affective aspects. With her affective opening up to everyone, the patient established a good bond with all the professionals in the home care team. It is considered that despite all her clinical difficulties, the patient demonstrated a will to live, her life had meaning, and she had feelings of self-efficacy, not giving in to difficult circumstances of her clinical condition.

The end of psychological treatment was recommended after the improvement concerning the initial demands: anxiety and aggression, better emotional management and social interaction. Therefore, the end of treatment was carried out through spacing out the sessions. At the end of 2019 and the beginning of 2020, weekly sessions became fortnightly for 6 months until a final session was carried out to close the case. At the final session, the patient demonstrated awareness of her assertive posture, calmer, and practicing daily relaxation and emotional management exercises.

\section{Techniques used with the patient and family in the process of home care:}

The techniques used in psychological treatment were based on cognitive behavioral therapy $(\mathrm{CBT})^{20}$. CBT employs a variety of strategies for knowing and understanding the factors that influence people's behavior concerning health to develop suitable intervention strategies ${ }^{22}$.

\section{Psychoeducation}

Psychoeducation ${ }^{24}$ provides the individual with the development of thoughts, ideas, and reflections on people, the world, and how to behave when faced with specific situations. It occurs through activities that collaborate precisely in reflection and obtaining values ${ }^{9}$. Psychoeducation is effective at guiding patient and family to, for example, the functioning of a disease, its diagnosis and symptoms, as well as treatment ${ }^{25-28}$.

Psychoeducation was used in different ways in the clinical case described here. It was used with the mother with oral and written orientations to understand of the patient's condition and her difficulties in activities of daily living ${ }^{29,30}$. Their routine was organized, as were medication times and key points for visitors and professionals. With the patient, psychoeducation was used through ludic stories for reflection, engagement, and understanding of difficulties such as anxiety and aggression, adequate management of emotions, and acquisition of new, more adaptive behaviors.

\section{Relaxation techniques}

Relaxation can be defined as a general effort to reduce the excitability of the organism. A way of relaxing is through breathing. An example of deep breathing is diaphragmatic, which fills the lungs with air, including the lower lungs, which generally are not used in breathing as the diaphragmatic musculature compresses the region meaning this small area is not well utilized. By moving the diaphragm down, that is, "filling the belly", it promotes inhalation. The vacuum existing between the diaphragm and the lungs makes them fill with air, resulting in good oxygenation. Moving the diaphragm up, that is, "pulling the belly in" promotes the complete emptying of the lungs, with the absence of $\mathrm{CO}_{2}$ residues. This type of breathing is calming ${ }^{25}$.

Diaphragmatic breathing can be allied with a relaxing mental image. In this technique, the patient is asked to allow a very calm image of something occurring to come to mind at some moment in their life. In the described case we included images and figures close to the patient's bed to help with imagination and attention, inducing a sensation of tranquility.

\section{Cognitive distraction}

Cognitive distraction involves a change of focus to other situations that may be agreeable and can often be found available in the home environment itself..25. An example is the use of this technique in patients with chronic pain. The attention directed at a pain increases the intensity of the painful experience and the distracting attention from the pain reduces the intensity of the painful experience ${ }^{21,31-33}$. Distraction was a technique that assisted in the management of the patient's aggression when a professional moved her limbs to stretch or stimulate. Its use was very positive as subsequently, the patient herself used it in her day-to-day life to change her aggressive behavior. The patient was acquiring new relaxing behavior and changing the cognitive focus, which enabled her to acquire a skill for her home treatment with the professionals involved.

\section{DISCUSSION}

Psychological home care aims to develop professional support within the reality of the home. The intervention may diminish the number of complications or hospital infections, as well as the participation of the family in patient care $^{34}$. Nevertheless, individual expectations should be considered when planning treatment in this type of support ${ }^{34}$. Home care enables more significant contact with the patient's specific reality, with the possibility of observing characteristics of the family dynamic that do not appear in sessions at healthcare institutions, which can and should be used for better management.

The limitations of psychological home care should be understood as related to the need for various types of technical adaptations. For example, the part of the house 
the psychological session can take place will depend on the patient's wishes, the permission to enter the bathroom, or the bedroom or being within the intimacy of the family. The psychologist will need to suggest the best way to carry out the treatment with the minimum interference at the time of the session in such a peculiar setting. The control of over the environment is very difficult, with interference at the time of treatment not being unusual? .

The techniques described and applied were crucial in the therapeutic intervention presented, their application when moving house, and acquiring new behaviors and emotional states making a significant difference to the patient's conduct. A study demonstrated that psychoeducational interventions could enable family caregivers and patients to feel more prepared and more competent ${ }^{34}$.

There is a growing interest in home care, reflecting the limitations of institutional treatment and the individual performance of the professionals $s^{34}$. When such limitations are considered, it is important to highlight that the home care is not developed through the transposition/application to the home environment of traditional institutional Psychology practices. Instead, the issue is the change of treatment setting and the perspective of the approach to issues to be worked. Indeed, the setting strongly characterizes the home visit, although it does not wholly define it.

Although teamwork is a common interlocution of psychologists in the healthcare area, expanding professional activities from the institution to the patient's home is a recent modality in the psychological practice. The home context holds unpredictability and instability, which requires the professional to find support in new theoretical references and methodologies contemplating the complexity of treatment. In addition, the direct contact with the way of life of families and challenges arising from this approximation leads to new reflections on professional ethics and a broadening of the concept of setting.

Few clinical cases resulting from schizocephaly are found in the literature. In addition to the clinical report, a review demonstrated the difficulty of finding cases in the literature, highlighting the importance of early diagnosis made by neuroimaging exams and adequate treatment, essential aspects to a good prognosis, and clinical response $\mathrm{e}^{35,36}$.

\section{CONCLUSION}

Home care may provide an opportunity to reorder the existing healthcare model. It also configures a new intersubjective and multiprofessional procedure aimed at seeking integral healthcare and quality of life to construct autonomy of the individuals in the humanized process of care. Psychological homecare enables autonomy. Therefore, it is important to carry out further studies that demonstrate knowledge and existing practices to develop improvements in home care.

\section{INDIVIDUAL CONTRIBUTIONS}

Luísa Pelucio and Marcia Cristina Nascimento Dourado - Contributed to the conception and design or analysis and interpretation of data.

Antonio Egidio Nardi and Michelle Levitan - Contributed to the writing of the article or critically reviewing it for important intellectual content.

\section{ACKNOWLEDGMENT}

Marcia Cristina Nascimento Dourado and Antonio Egidio Nardi are researchers funded by CNPq.

\section{CONFLICTS OF INTEREST}

Authors do not have conflicts interests to declare. There was no funding.

\section{REFERENCES}

1. Kerber NP, Kirchhoff AL. Home care and its relationship to the work environment in health. Cad Saúde Pública. 2008;24(3).

2. Yakovlev PI, Wadsworth RC. Schizencephalies; a study of the congenital clefts in the cerebral mantle; clefts with hydrocephalus and lips separated. J Neuropathol Exp Neurol. 1946;5:169-206.

3. Barkovich AJ, Norman D. MR imaging of schizencephaly. AJR Am J Roentgenol. 1988;150:1391-6

4. Denis D, Chateil JF, Brun M, Brissaud 0, Lacombe D, Fontan D, et al. Schizencephaly: Clinical and imaging features in 30 infantile cases. Brain Dev. 2000;22:475-83

5. Halabuda A, Klasa L, Kwiatkowski S, Wyrobek L, Milczarek 0, Gergont A. Schizencephaly diagnostics and clinical dilemmas. Childs Nerv Syst. 2015;31:551-6.

6. Feudtner C, Feinstein JA, Satchell M, Zhao H, Kang TI. Shifting place of death among children with complex chronic conditions in the United States, 1989-2003. JAMA. 2007;297(24):2725-32.

7. Nageswaran S, Radulovic A, Anania A. Transitions to and from the acute inpatient care setting for children with life-threatening illness. Pediatr Clin North Am. 2014;61(4):761-83.

8. Malcolm C, Knighting K, Forbat L, Kearney N. Prioritization of future research topics for children's hospice care by its key stakeholders: A Delphi study. Palliat Med. 2009 23:398405.

9. Jones J, Wilson A, Parkes M, Wynn A, Jagger C, Spiers N, et al. Economic evaluation of hospital at home versus hospital care: cost minimisation analysis of data from randomised controlled trial. BMJ. 1999;319(7224):1547-50.

10. Landi F, Gambassi G, Pole R, Tabaccanti S, Cavinato PV, Bernabei R. Impact of integrated home care services on hospital use. J Am Geriatr. 1999;47(12):1430-4.

11. Baumgardner DJ, Burtea ED. Quality-of-life in technology-dependent children receiving home care, and their families: a qualitative study. WMJ. 1998;97:51-5.

12. O'Brien ME. Living in a house of cards: family experiences with long-term childhood technology dependence. J Pediatric Nurs. 2001;16:13-22. 
13. Howgego IM, Yellowlees P, Owen C, Meldrum L, Dark F. The therapeutic alliance: the key to effective patient outcome? A descriptive review of the evidence in community mental health case management. Aust N Z J Psychiatry. 2003;37(2):169-83.

14. American Psychological Association (APA). Guidelines for psychological practice with older adults. Washington, DC: APA; 2004.

15. Haddad L. A ecologia da educação infantil: construindo um modelo de sistema unificado de cuidado e educação [tese de doutorado]. São Paulo: Universidade de São Paulo; 1997.

16. Chen Y, Abel KT, Janecek JT, Chen Y, Zheng K, Cramer SC. Home-based technologies for stroke rehabilitation: A systematic review. Int J Med Inform. 2019;123:11-22.

17. Goodwin FFK, Jamison KR. Manic-Depressive IIIness. New York: Oxford University Press; 1990.

18. Zimerman D. Fundamentos Psicanalíticos. Porto Alegre: Artmed; 1999.

19. Floriani CA, Schramm FR. Home care for the elderly: problem or solution? Cad Saúde Pública. 2004;20(4):986-94.

20. Costa AS, Santos CCT, Costa LMS, Ximenes MR, Silva PHG. Esquizencefalia: relato de caso. Rev Inic Cient Ext. 2018; 1(2):88-90.

21. Turk CD, Gatchel JR. Psychological approaches to pain management: a practitioner's handbook. New York: The Guilford Press; 1996.

22. Amaral JGP, Yanaga RH, Geissler HJ, Carvalho Neto A, Bruck I, Antoniuk SA. Esquizencafalia: relato de onze casos. Arq Neuro-Psiquiatr. 2001;59(2A).

23. Rodrigues MCS, Monteiro AMV, Llerena Junior JC, Fernandes AR. Aspectos clínicos em 16 pacientes com diagnóstico tomográfico de esquizencefalia. Radiol Bras. 2006;39(5).

24. Gomes IM. The domiciliary health care and its state of art: a bibliographic study. Online Braz J Nurs. 2008;7(3).
25. Beck AT. The current state of cognitive therapy: a 40 year retrospective. Arch Gen Psychiatry. 2005;62(9):953-9.

26. Pereira FM. Theorical Practice Applicability of Cognitive Behavior Therapy in Hospital Psychology. Rev Bras Ter Cogn. 2010;7(3).

27. Turk CD, Gatchel JR. Psychological approaches to pain management: a practitioner's handbook. New York: The Guilford Press; 1996.

28. Knapp P, LuzE, Baldisserotto Psicoterapias cognitivo-comportamentais: um diálogo com 0 psiquiatra. Porto Alegre: Artmed; 2001.

29. Pereira FM. Theorical Practice Applicability of Cognitive Behavior Therapy in Hospital Psychology. Rev Bras Ter Cogn. 2010;6(2).

30. Barsky AJ. Patients who amplify bodily sensations. Ann Inter Med. 1979;91(1):63-70.

31. McCracken LM. "Attention" to pain in persons with chronic pain: a behavioral approach. Behav Ther. 1997;28:271-84.

32. Keefe FJ, Dunsmore J, Burnett R. Behavioral and cognitive-behavioral approaches to chronic pain: recent advances and future directions. J Consult Clin Psychol. 1992;60(4):528-36.

33. Pincus T, Morley S. Cognitive-processing bias in chronic pain: a review and integration. Psychol Bull. 2001;127(5):599-617.

34. Wennman-Larsen A, Tishelman C. Advanced home care for cancer patients at the end of life: a qualitative study of hopes and expectations of family. Scand J Caring Sci. 2002;16(3):240-7.

35. Ugboma EW, Agi CE. Schizencephaly: A case report and review of literature. Niger Postgrad Med J. 2016;23(1):38-40.

36. Tylš F, Brunovský M, Šulcová K, Kohútová B, RyznarováZ, Kopeček M. Latent Schizencephaly With Psychotic Phenotype or Schizophrenia With Schizencephaly? A Case Report and Review of the Literature. Clin EEG Neurosci. 2019;50(1):13-19. 